\title{
R\&D for Clean Energy Production Through Responsible Utilization of Various Feedstocks Including Coal, Biomass, and Hydrocarbons
}

\author{
Rachid B. Slimane
}

\author{
Keywords \\ Renewable energy $\bullet$ Biomass $\bullet$ Gasification $\bullet$ Syngas cleaning and conditioning \\ Tars reforming $\bullet$ Hot gas filtration $\bullet$ Syngas conversion $\bullet$ Biomass-to-liquids \\ Green gasoline
}

Coal, natural gas, and oil account for close to $90 \%$ of the energy consumed globally. The significance of these crucial feedstocks to key global economies cannot be overstated, and despite growing concerns related to Climate Change, reliance on these fuels is not going away any time soon. Despite well-established conventional approaches to utilizing these feedstocks (e.g. coal combustion for power generation), an incredible amount of research has been underway for decades to improve both the utilization efficiency and environmental performance, leading to the emergence of a number of promising technologies. Furthermore, significant efforts have been devoted to utilize renewable energy sources, such as $\mathrm{CO}_{2}$-neutral biomass, despite their relative scarcity and other challenges associated with their utilization.

The main objective of this talk was to share related experiences with early-career scientists participating in this initial conference. The author will briefly discuss the dynamics in the energy sector, before presenting on specific R\&D areas from his own experience during over 19 years at the Gas Technology Institute in pilot-scale projects aimed at demonstration testing of several gasification-based technologies. GTI has state-of-the-art test platforms capable of demonstrating coal and biomass gasification in bubbling fluidized-bed gasifiers; syngas reforming (tars, methane, and light hydrocarbons); cleaning (including ammonia destruction and hot syngas filtration via candle filters), and conditioning; and enabling long-term operation of the various unit operations in an integrated fashion. Consistent with the

\section{R. B. Slimane $(\square)$}

Olefins \& Aromatics, Technology Management, Petrochemicals, SABIC Technology Center-Riyadh (STC-R), 2nd Industrial Area, Kharj Hwy, Riyadh, 11551, Saudi Arabia

e-mail: slimaner@sabic.com broad Topic 6 of the conference, particular emphasis will be placed on a suite of processes, which were neatly integrated to produce gasoline from woody biomass at up to $4.5 \mathrm{MWth}$ (input) scale. The various steps in this very promising biomass-to-liquids (BTL) technology will be explained to highlight the various $\mathrm{R} \& \mathrm{D}$ areas involved, and most importantly to impress upon the early-career scientists how fundamental principles play key roles in devising and integrating the technology building blocks. The need to equip the overall test facility with innovative sampling and analytical systems, will also be discussed, as a necessary measure to optimize the process.

\section{Author Biography}

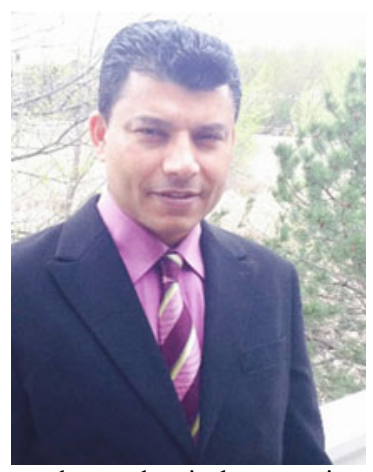

Dr. Rachid Slimane is a Staff Scientist in the Olefins and Aromatics Technology Development department at the SABIC Technology Center in Riyadh. He joined SABIC two years ago, and has since been focused on the scale-up of a proprietary catalytic panel-reactor technology for the selective production of propylene through propane dehydrogenation. Prior to joining SABIC, Dr. Slimane had close to 20 years of broad contract R\&D experience at the Gas Technology Institute (GTI in Des Plaines, Illinois, USA), with strong focus on thermochemical conversion (gasification), materials development, gas cleaning \& conditioning, and chemical processes R\&D in general.

Dr. Slimane obtained Bachelor's, Master's, and Ph.D. degrees from Colorado School of Mines, the University of Missouri-Rolla, and the University of Minnesota. He holds four (4) patents and has contributed over twenty-five (25) peer-reviewed journal articles and numerous technical reports and conference papers and presentations. 